\title{
Knowledge and Anxiety Level of Dentists about COVID-19 Pandemic
}

\author{
Olcay Özdemir ${ }^{1}$, Ecehan Hazar², Sibel Koçak ${ }^{3}$, Baran C Sağlam ${ }^{4}$, Mustafa M Koçak ${ }^{5}$
}

\begin{abstract}
Aim: This study aimed to assess the knowledge and anxiety levels of dentists and pregraduate dental students about COVID-19 in Turkey. Materials and Methods: A three-part online questionnaire was used to collect data. Questionnaire 1 consisted of 10 demographic questions. In questionnaire 2, there were 10 multiple-choice questions, including various COVID-19 knowledge. In questionnaire 3, participants were tested by a self-evaluation test as Worry and Anxiety Questionnaire (WAQ).

Results: A total of 1002 respondents had completed the questionnaires. The majority of the participants exhibited very good knowledge. Worry and anxiety scores differ by gender, institution, and specialty $(p<0,001)$. There was no significant relationship between knowledge level and stress level $(p>0,050)$.

Conclusion: Female dentists, pediatric dentists, and dentists working in public hospitals in Turkey were found to be significantly more stressed. The level of knowledge was generally high and no correlation was established by the level of anxiety.

Clinical Significance: In this global pandemic process, it is known that all dentists' problems and needs are common, and the effects of the disease on the dental profession can be globalized. It is crucial in the face of the anxiety and stress demonstrated by dentists during COVID-19 that mental coping mechanisms and strategies generated to remain calm and function efficiently.

Keywords: Anxiety, Coronavirus, Covid-19, Dentistry, Questionnaire-based study.

Journal of Oral Health and Community Dentistry (2020): 10.5005/jp-journals-10062-0084
\end{abstract}

\section{INTRODUCTION}

On December 31, 2019, 27 patients with clinical symptoms of fever, dry cough, dyspnea, bilateral lung infiltrates on computed tomography (CT) imaging, and fatigue were identified in Wuhan City in China. ${ }^{1,2}$ The etiology of the disease was unknown, but the cases were related to a single local seafood market, where trades in live wild animal species and fish. ${ }^{1}$ The infectious agent obtained from the throat swab samples was identified as a novel coronavirus, and pneumonia caused by the virus was called COVID-19 by the World Health Organization (WHO). ${ }^{3}$ COVID-19 is caused by a beta coronavirus ( $\beta-\mathrm{CoV}$ ) and comprised of a singlestranded ribonucleic acid (RNA) structure. ${ }^{4}$ The virus has shown a typical structure sequence like the other coronaviruses, and it has genomic similarities with severe acute respiratory syndrome coronavirus (SARS-CoV) (about 79\%) and Middle East respiratory syndrome coronavirus (MERS-CoV) (about 50\%). ${ }^{5} 8$ of the 14 amino acids in the SARS-CoV were conserved in the novel coronavirus. ${ }^{6}$ Subsequently, the International Committee on Taxonomy of Viruses (ICTV) named this novel virus "SARS-CoV-2" due to the phylogenetic and taxonomic analysis. ${ }^{5}$

According to recent research, a similar genomic sequence between a $\beta$-CoV obtained from the bat and SARS-CoV- 2 was $96.2 \%$. $^{7}$ Additionally, researchers from South China found that $70 \%$ of the pangolins contain $\beta-\mathrm{CoV}$. They indicated that the genomic similarity of SARS-CoV- 2 with one of the obtained $\beta-\mathrm{CoV}$ from pangolin was $99 \%$ and stated that the pangolin may be the intermediate host. ${ }^{8}$

Coronaviruses belong to the family of Coronaviridae cause diseases in vertebrates including pigs, camels, bats, and birds. Sometimes virus transmission to humans can cause mild
${ }^{1}$ Faculty of Dentistry, Department of Paediatric Dentistry, Zonguldak Bülent Ecevit University, Kozlu 67600, Zonguldak, Turkey

${ }^{2-5}$ Faculty of Dentistry, Department of Endodontics, Zonguldak Bülent Ecevit University, Kozlu 67600, Zonguldak, Turkey

Corresponding Author: Olcay Özdemir, Faculty of Dentistry, Department of Paediatric Dentistry, Zonguldak Bülent Ecevit University, Kozlu, Zonguldak, Turkey, Phone: +90 5305470120, e-mail: ozdemir.olcay@yahoo.com

How to cite this article: Özdemir O, Hazar E, Koçak S, et al. Knowledge and Anxiety Level of Dentists about COVID-19 Pandemic. J Oral Health Comm Dent 2020;14(3):104-109.

Source of support: Nil

Conflict of interest: None

upper respiratory tract infections. However, three times in the 21st-century coronavirus outbreaks have emerged to cause fatal disease and global transmission concerns. Seven coronaviruses are known to cause human disease, four of which are mild: viruses 229E, OC43, NL63, and HKU1. Three members of the coronaviruses can have more serious diseases in humans, and those are SARSCoV (SARS, severe acute respiratory syndrome), which explored in 2002-2004; MERS-CoV (Middle East respiratory), which emerged in 2012; and SARS-CoV-2 (COVID-19), which emerged in late 2019.

COVID-19 is a novel outbreak and there is limited information regarding risk factors for severe diseases. With the SARS-CoV-2 virus spread to different countries and rapidly increasing transmission, WHO declared the COVID-19 outbreak as a pandemic on March 11, 2020. Since December 2019, 16,114,449 laboratory-confirmed cases

(c) The Author(s). 2020 Open Access This article is distributed under the terms of the Creative Commons Attribution 4.0 International License (https:// creativecommons.org/licenses/by-nc/4.0/), which permits unrestricted use, distribution, and non-commercial reproduction in any medium, provided you give appropriate credit to the original author(s) and the source, provide a link to the Creative Commons license, and indicate if changes were made. The Creative Commons Public Domain Dedication waiver (http://creativecommons.org/publicdomain/zero/1.0/) applies to the data made available in this article, unless otherwise stated. 
of COVID-19 have been reported by the World Health Organization (WHO) with 646,641 related deaths in 216 countries, areas, or territories till this report is written. ${ }^{9}$

Initially, studies show the possibility of virus transmission from animal to human, while studies have also shown that SARSCoV-2 is transmitted from person to person through direct droplet inhalation or contact with oral, nasal, or eye membranes. ${ }^{10-13}$

Dental professionals are very frequently exposed to saliva or bioaerosols that can lead to an increased risk of infection generated during certain dental treatments. Bioaerosols occur during treatment in an asymptomatic but infected patient and carry the viruses through airborne ${ }^{14}$ and these bioaerosols can pass through the pores of the masks or contaminate environmental surfaces. ${ }^{15,16}$ Hence, dentists are at great risk of exposing this infection or become a source of transmission to patients, coworkers, or family. The presence of this fatal virus among healthcare workers underscores a need for continuing efforts toward COVID-19 disease (SARS-CoV-2) awareness.

The pandemic due to the COVID-19 disease may cause anxiety and limit their clinical practice. Currently, there is no information about the psychological impact and mental health of Turkish dentists during the peak of the COVID-19 pandemic because of the risks and the standard protective measures. In daily clinical work, standard protection may not be effective enough to prevent the spread of this outbreak, especially when patients are in the incubation period, unaware of being infected, or choose to conceal their infection. This study aimed to assess the knowledge and anxiety levels of dentists and pregraduate dental students about COVID-19 in Turkey.

\section{Materials and Methods}

The study was approved by the Zonguldak Bülent Ecevit University Human Research Ethics Committee (Protocol Number: 789/20.05.2020) and the Republic of Turkey, Ministry of Health, Scientific Research Platform (Protocol Number: 2020-0623T13_02_07). A total of 1002 dentists and pregraduate students were accepted to participate in the present study.

A three-part online questionnaire was used to collect data (https://docs.google.com/forms/). The participants reached the survey by clicking on the link via social media community groups, e-mail, and other communication media. The survey was available for about 5 days. The identity of the participants remained confidential.

Questionnaire 1 consisted of 10 demographic questions, including dentists' age, gender, marital status, having any children, children nursemaid, contact of geriatric people, education level, profession, self-evaluation of COVID-19 knowledge, and anxiety level (Table 1). In questionnaire 2, there were 10 multiple-choice questions, including various COVID-19 knowledge (Table 2). The questions on the survey were prepared by the authors after reviewing related literature, studies, and international guidelines. ${ }^{5,17-20}$

In questionnaire 3, participants were tested by a self-evaluation test as Worry and Anxiety Questionnaire (WAQ) developed by Dugas and Francis ${ }^{21}$ (Table 3). There were 10 questions that measure the anxiety issues, excessive and uncontrollable aspect of anxiety, duration and frequency of the disorder, somatic symptoms, anxiety and anxiety-related helplessness, and intervention in life. For the total score on the WAQ, the scores were added up to the responses for each of the items. To meet anxiety level on the WAQ, one must
Table 1: Demographic characteristics and WAQ score distribution of the participants

\begin{tabular}{lrr}
\hline & $(n)$ & $(\%)$ \\
\hline Gender & & \\
$\quad$ Female & 703 & 70,2 \\
Male & 299 & 29,8 \\
Marital status & & \\
$\quad$ Married & 305 & 30,4 \\
Single & 697 & 69,6 \\
Having any children & & \\
No & 771 & 76,9 \\
Yes & 231 & 23,1 \\
Children nursemaid* & & \\
Family member (under the age of 60) & 75 & 34,0 \\
Family member (over the age of 60) & 56 & 25,6 \\
$\quad$ Nursemaid (under the age of 60) & 53 & 24,2 \\
$\quad$ Nursemaid (over the age of 60) & 3 & 1,4 \\
Old enough to not need care & 23 & 10,5 \\
$\quad$ Other & 14 & 6,0
\end{tabular}

Are there any members over the age of 60 with whom you have close contact within the family?

No

$636 \quad 63,5$

Yes

$366 \quad 36,5$

Institution

Faculty of dentistry $583 \quad 58,2$

$\begin{array}{llll}\text { Private clinic } & 254 & 25,3\end{array}$

$\begin{array}{lrl}\text { Public hospital } & 178 & 17,8\end{array}$

Expertise

Pregraduate student 41141,0

$\begin{array}{lll}\text { General dentist } & 329 & 32,8\end{array}$

$\begin{array}{llll}\text { Endodontics } & 66 & 6,6\end{array}$

$\begin{array}{llll}\text { Pediatric dentistry } & 47 & 4,7\end{array}$

Periodontology $\quad 46 \quad 4,6$

$\begin{array}{lll}\text { Prosthodontics } & 37 & 3,7\end{array}$

$\begin{array}{lll}\text { Orthodontics } & 19 & 1,9\end{array}$

$\begin{array}{lll}\text { Restorative dentistry } & 17 & 1,7\end{array}$

Dento-maxillofacial radiology $\quad 16 \quad 1,6$

Oral and maxillofacial surgery $\quad 14 \quad 1,4$

Did the impact of the COVID-19 pandemic on Turkey affect you psychologically?

$\begin{array}{lrl}\text { Yes } & 865 & 86,3\end{array}$

$\begin{array}{lll}\text { No } & 61 & 6,1\end{array}$

$\begin{array}{lll}\text { I'm not sure } & 76 & 7,6\end{array}$

How would you assess your level of knowledge about the COVID-19 pandemic?

Enough

60260,1

Not enough

919,1

WAQ General (items 1,2,3,10)

Not providing the criteria

84083,8

Report a score of "4" or higher

16216,2

WAQ Cognitive criteria (items $1,2,3$ )

Not providing the criteria

80980,7

Report a score of "4" or higher

$193 \quad 19,3$

WAQ Somatic criteria (items 4-9)

Not providing the criteria

$458 \quad 45,7$

Report a score of " 4 " or higher on at least 3 of the $\quad 54454$ 6 somatic symptoms

$(p<0,05)$ 
Table 2: Correct answer distributions of questions

\begin{tabular}{|c|c|c|}
\hline & $(n)$ & $(\%)$ \\
\hline \multicolumn{3}{|l|}{ COVID-19 is caused by } \\
\hline Correct (SARS-CoV-2) & 609 & 60,8 \\
\hline Incorrect & 393 & 39,2 \\
\hline \multicolumn{3}{|l|}{ COVID-19 patients develop } \\
\hline Correct (severe acute respiratory illness) & 991 & 98,9 \\
\hline Incorrect & 11 & 1,1 \\
\hline \multicolumn{3}{|l|}{ COVID-19 can be fatal for } \\
\hline $\begin{array}{l}\text { Correct (people with diabetes, cancer, and other } \\
\text { chronic diseases) }\end{array}$ & 983 & 98,1 \\
\hline Incorrect & 19 & 1,9 \\
\hline \multicolumn{3}{|l|}{ Incubation time for the virus is } \\
\hline Correct (1-14 days) & 986 & 98,5 \\
\hline Incorrect & 16 & 1,5 \\
\hline \multicolumn{3}{|c|}{$\begin{array}{l}\text { Vaccination or medication of COVID-19 is available on the } \\
\text { market }\end{array}$} \\
\hline Correct (No) & 998 & 98,6 \\
\hline Incorrect & 4 & 0,4 \\
\hline \multicolumn{3}{|l|}{ Can use to diagnose COVID-19 } \\
\hline Correct (PCR) & 500 & 49,9 \\
\hline Incorrect & 502 & 50,1 \\
\hline \multicolumn{3}{|l|}{$\begin{array}{l}\text { There is a high risk of nosocomial infection in dental } \\
\text { interventions for COVID-19 }\end{array}$} \\
\hline Correct (Yes) & 997 & 99,5 \\
\hline Incorrect & 5 & 0,5 \\
\hline
\end{tabular}

The standard protection measures in daily clinical work are effective enough to prevent the spread of COVID-19, especially when patients are in the incubation period, are unaware they are infected or choose to conceal their infection

Correct (No)

$979 \quad 97,7$

Incorrect

$25 \quad 2,3$

If a dental treatment is to be performed, what is the most appropriate mouthwash before treatment?

Correct (hydrogen peroxide \%1, povidone-iodine 0,2\%) $387 \quad 38,6$

Incorrect

61561,4

Which one of the drugs that is not recommended to be used especially for COVID-19 disease?

Correct (ibuprofen)

$357 \quad 35,6$

Incorrect

$645 \quad 64,4$ report at least one worry theme, report a score of " 4 " or higher on items 1, 2, 3, and 10, as well as report a score of "4" or higher on at least 3 of the 6 somatic symptoms.

Three other categories of criteria can be met: cognitive criteria (a score of "4" or higher on items 1, 2, and 3), somatic criteria (a score of " 4 " or higher on at least 3 of the 6 somatic symptoms on items 4, 5, 6, 7, 8, and 9), and no criteria (does not meet any of the above categories).

Statistical analysis was performed with SPSS software (SPSS V23; IBM Corp., Armonk, New York, USA). Data were analyzed using Kolmogorov-Smirnov test. Mann-Whitney $U$ and Kruskal-Wallis tests were used to determine the difference between groups for categorical variables. The relationship between variables was examined by Spearman's correlation analysis. The level of significance was set at a $p$-value of less than 0.05 .
Table 3: Worry and anxiety questionnaire

\begin{tabular}{|c|c|c|c|c|c|c|c|c|}
\hline \multicolumn{9}{|c|}{ Questions/scoring } \\
\hline \multicolumn{9}{|c|}{ Do your worries seem excessive or exaggerated? } \\
\hline \multicolumn{3}{|c|}{ Not at all excessive } & \multicolumn{3}{|c|}{ Moderately excessive } & \multicolumn{3}{|c|}{ Totally excessive } \\
\hline 0 & 1 & 2 & 3 & 4 & 5 & 6 & 7 & 8 \\
\hline
\end{tabular}

Over the past 3 months, how many days have you been bothered by excessive worry?

\begin{tabular}{|l|l|l|l|l|l|l|l|l}
\hline \multicolumn{3}{c|}{ Never } & \multicolumn{3}{c|}{1 day out of 2} & \multicolumn{3}{|c}{ Every day } \\
\hline 0 & 1 & 2 & 3 & 4 & 5 & 6 & 7 & 8 \\
\hline
\end{tabular}

Do you have difficulty controlling your worries? For example, when you start worrying about something, do you have difficulty stopping?

\begin{tabular}{l|c|c|c|c|c|c|c|c}
\hline \multicolumn{3}{c|}{ No difficulty } & \multicolumn{3}{c|}{ Moderate difficulty } & \multicolumn{3}{c}{ Extreme difficulty } \\
\hline 0 & 1 & 2 & 3 & 4 & 5 & 6 & 7 & 8 \\
\hline Restlessness or feeling keyed up or on edge \\
\hline \multicolumn{3}{c|}{ Moderately } & \multicolumn{4}{c}{ Very severely } \\
\hline 0 & 1 & 2 & 3 & 4 & 5 & 6 & 7 & 8 \\
\hline
\end{tabular}

\begin{tabular}{|c|c|c|c|c|c|c|c|c|}
\hline \multicolumn{9}{|c|}{ Being easily fatigued } \\
\hline \multicolumn{3}{|c|}{ Not at all } & \multicolumn{3}{|c|}{ Moderately } & \multicolumn{3}{|c|}{ Very severely } \\
\hline 0 & 1 & 2 & 3 & 4 & 5 & 6 & 7 & 8 \\
\hline \multicolumn{9}{|c|}{ Difficulty concentrating or mind going blank } \\
\hline \multicolumn{3}{|c|}{ Not at all } & \multicolumn{3}{|c|}{ Moderately } & \multicolumn{3}{|c|}{ Very severely } \\
\hline 0 & 1 & 2 & 3 & 4 & 5 & 6 & 7 & 8 \\
\hline \multicolumn{9}{|c|}{ Irritability } \\
\hline \multicolumn{3}{|c|}{ Not at all } & \multicolumn{3}{|c|}{ Moderately } & \multicolumn{3}{|c|}{ Very severely } \\
\hline 0 & 1 & 2 & 3 & 4 & 5 & 6 & 7 & 8 \\
\hline \multicolumn{9}{|c|}{ Muscle tension } \\
\hline \multicolumn{3}{|c|}{ Not at all } & \multicolumn{3}{|c|}{ Moderately } & \multicolumn{3}{|c|}{ Very severely } \\
\hline 0 & 1 & 2 & 3 & 4 & 5 & 6 & 7 & 8 \\
\hline
\end{tabular}

Sleep disturbance (difficulty falling or staying asleep, or restless unsatisfying sleep)

\begin{tabular}{c|c|c|c|c|c|c|c|c}
\hline \multicolumn{3}{c|}{ Not at all } & \multicolumn{3}{c|}{ Moderately } & \multicolumn{3}{c}{ Very severely } \\
\hline 0 & 1 & 2 & 3 & 4 & 5 & 6 & 7 & 8 \\
\hline
\end{tabular}

To what extent does worry or anxiety interfere with your life? For example, your work, social activities, family life, etc.?

\begin{tabular}{c|c|c|c|c|c|c|c|c}
\hline \multicolumn{3}{c|}{ Not at all } & \multicolumn{3}{c|}{ Moderately } & \multicolumn{3}{c}{ Very severely } \\
\hline 0 & 1 & 2 & 3 & 4 & 5 & 6 & 7 & 8 \\
\hline
\end{tabular}

\section{Results}

A total of 1002 respondents had completed the questionnaires. The demographic characteristics of participants are presented in Table 1. The majority of respondents were women $(70,2 \%)$, aged 20 to 40 years $(86,3 \%)$, single $(69,6 \%)$, and with no child (76,9\%). $36.5 \%$ of the participants stated that they had close contact with individuals over 60 years old in the family. $41 \%$ were pregraduate students, $32,9 \%$ general dentists and the others were specialists. The majority of the participants work in the university hospital (58,3\%), private clinic, and public oral and dental health center, respectively. About $60,1 \%$ participants reported that they had enough knowledge about COVID-19 pandemic, and $86,3 \%$ stated that the pandemic affects them psychologically. 
Table 4: Comparisons by WAQ score (total score)

\begin{tabular}{llll}
\hline & $\begin{array}{l}\text { Median } \\
(\min -\max )\end{array}$ & $\begin{array}{l}\text { Statistical } \\
\text { analysis }\end{array}$ & $p$ \\
\hline $\begin{array}{l}\text { Gender } \\
\text { Female }\end{array}$ & $39(0-80)$ & & \\
$\quad \begin{array}{l}\text { Male } \\
\text { Marital status } \\
\text { Married } \\
\text { Single }\end{array}$ & $26(0-80)$ & $U=72252$ & $<\mathbf{0 , 0 0 1}$ \\
$\begin{array}{l}\text { Children } \\
\text { No } \\
\text { Yes }\end{array}$ & $36(3-80)$ & & \\
& $35(0-80)$ & $U=98168$ & 0,054 \\
& $35(0-80)$ & & \\
& $36(0-79)$ & $U=96334,5$ & 0,059
\end{tabular}

Are there any members over the age of 60 with whom you have close contact within the family?

\begin{tabular}{|c|c|c|c|}
\hline No & $34,5(0-80)$ & \multirow{2}{*}{$U=123590$} & \multirow{2}{*}{0,102} \\
\hline Yes & $36(1-80)$ & & \\
\hline \multicolumn{4}{|l|}{ nstitution } \\
\hline Faculty of dentistry & $33(0-80) b$ & & \\
\hline Private clinic & $34(0-80) b$ & $U=31,182$ & $<0,001$ \\
\hline Public hospital & $43(0-80) a$ & & \\
\hline \multicolumn{4}{|l|}{ xpertise } \\
\hline Pregraduate student & $31(0-80)$ & & \\
\hline General dentist & $37(0-80)$ & & \\
\hline Endodontics & $39(0-79)$ & & \\
\hline Pediatric dentistry & $44(9-67)$ & & \\
\hline Periodontology & $35(0-72)$ & & \\
\hline Prosthodontics & $37(5-68)$ & $U=38,146$ & $<0,001$ \\
\hline Orthodontics & $31(4-60)$ & & \\
\hline Restorative dentistry & $42(14-79)$ & & \\
\hline Dentomaxillofacial radiology & $37,5(5-79)$ & & \\
\hline $\begin{array}{l}\text { Oral and maxillofacial } \\
\text { surgery }\end{array}$ & $24(0-46)$ & & \\
\hline
\end{tabular}

$U$, Mann-Whitney $U$ test, Kruskal-Wallis test (a-b, there is no difference between groups with the same letter); $r$, Spearman's correlation coefficient $(p>0.050)$

Table 2 describes the general knowledge of the dentists about COVID-19. Most of the respondents were correctly aware of the pandemic. A total of 909 (90,7\%) participants exhibited very good knowledge (the correct answer to 7 or more questions). Poor knowledge was more obvious in questions related to the pathogen coronavirus name (SARS-CoV-2), diagnostic test (PCR), type of recommended mouth rinse before dental procedures ( $1 \%$ hydrogen peroxide, $0,2 \%$ povidone), and drug which was not recommended for use (ibuprofen) as shown in Table 2. The mean knowledge score was 7,86, maximum and minimum scores were 10 and 3 , respectively.

Tables 1 and 4 describe the anxiety level and psychological impact of the pandemic. The ratio of those who marked 4 and above to the 1-2-3-10 questions (general worry and anxiety level) was $16.2 \%$, and $1-2-3$ (cognitive symptoms) was $19.3 \%$. The ratio of those who marked 4 or more in at least 3 of $4-5-6-7-8-9$ questions was $54.3 \%$. The results showed that the majority of the participants demonstrated somatic symptoms such as discomfort, tiredness, and sleep disturbance. $16.2 \%$ of the participants were affected by the COVID-19 outbreak at a level that could be diagnosed with an anxiety disorder (Table 1).

A comparison of demographic data and the anxiety level was given in Table 4 . Worry and anxiety scores differ by gender $(p<0,001)$. Female dentists were found to be more psychologically affected by the COVID-19 outbreak and the scores varied according to the institution $(p<0,001)$. The difference arose from the fact that the WAQ scores of the employees working in the public hospital were higher than the other groups. There was a significant difference in the specialty $(p<0,001)$. The WAQ scores of pediatric dentists were higher than the other categories. There was no difference between WAQ scores and marital status, presence of children, or familiar contact with individuals over the age of 60 $(p>0,050)$.

There was no significant relationship between knowledge level and stress level $(p>0,050)$ (Table 4).

\section{Discussion}

Mental implications such as fear and anxiety are possible in pandemics, especially when the number of infected persons and mortality rates increases at an alarming level. ${ }^{22} \mathrm{~A}$ metaanalysis study reported that meta-analyses were published and reported that early evidence that a high proportion of healthcare professionals experience significant levels of anxiety, depression, and insomnia during the current viral outbreak. ${ }^{23}$ Besides, the COVID-19 pandemic has negatively affected the daily routine of dentists. ${ }^{24}$ Since it has been reported that the primary route for transmission of COVID-19 is through droplets and aerosols, ${ }^{25}$ dental procedures have been suspended because of the risk of nosocomial infection and transmission during dental treatments. This enhances the likelihood of dentists and dental healthcare workers getting infected and further spreading the virus. Recent studies reported that a large number of dentists fear getting infected with COVID-19 from their patients or coworkers who provide high psychological tension. ${ }^{22,26}$

The most appropriate way to determine emotions, thoughts, and experiences on the subject like anxiety levels, knowledge of the general or special population is questionnaire-based studies. The suitability of the questionnaire-based studies are proven for gathering data of participants; however, careful collection of data and interpretation is required. ${ }^{27}$ This study used an online questionnaire to evaluate Turkish dentists' knowledge and anxiety levels about the COVID-19 infection. The authors aimed to understand the mental impact and knowledge of Turkish dentists during the current viral outbreak after the beginning of the lockdown period.

To the best of our knowledge, the anxiety level of Turkish dentists was evaluated for the first time in the COVID-19 outbreak. The participation rates by gender and age were similar to a systematic review and meta-analysis of Pappa et al. ${ }^{23}$ In most studies, the majority of the participants were women and the majority of the age range was 20 to 40 . The fact that female participants show more interest in the study may be related to the level of experienced anxiety. The common point of anxiety assessment studies in the COVID-19 outbreak is that females were more affected by the pandemic. ${ }^{28}$ Similarly, our results supported this finding female group demonstrated a higher anxiety level with a significant difference when compared to the male group.

When the literature was reviewed, no information is available about the anxiety levels of the dentists during the pandemic 
in terms of their areas of expertise. In our study, we found that pediatric dentists' anxiety levels were higher than others have. A study of the epidemiology of COVID-19 among children in China reported that regarding the severity (including both confirmed and suspected cases), 4.4 and $51.0 \%$ of cases were diagnosed as asymptomatic and mild symptoms, respectively. ${ }^{29}$ These results indicate that it was difficult to distinguish whether a patient who applied to the clinic has COVID positive and providing clinical care for the affected children may be potentially spread the infection. However, postponing appointments can also cause serious infections. These complex conditions may cause pediatric dentists to have higher levels of stress. Besides, due to the protective equipment they wear, the psychological rejection of the patients to be treated and the inability to carry out a controlled treatment during the procedure may also put pressure on them.

According to the results of this study, public hospital employee dentists have a higher level of anxiety. Although dental treatments performed during the outbreak were limited to emergency procedures, dentists working in public hospitals were assigned to be included in testing teams to identify and isolate possible COVID19 cases in Turkey. This caused public employee dentists to be in contact with many COVID-19 positive patients. That is why they are more likely to experience anxiety than other group dentists.

In Turkey, it was constituted a committee of experts that includes medical specialists in the field before the emergence of the pandemic and gave great importance to the establishment of public information. ${ }^{30}$ Therefore, the majority of the participants have sufficient knowledge about novel coronavirus disease. Questions with general information about the disease were answered with a great correct proportion. That is why no significant correlation was found between the level of anxiety and knowledge.

The current study provides preliminary data about the impact of COVID-19 on mental health for Turkish dentists. Findings can help to quantify support needs. It is crucial in the face of the anxiety and stress demonstrated by dentists during COVID-19 that mental coping mechanisms and strategies that generated to remain calm and function efficiently.

\section{CONCLUSION}

As a result of this questionnaire-based study, female dentists, pediatric dentists, and dentists working in public hospitals in Turkey were found to be significantly more stressed. The level of knowledge was generally high and no correlation was established by the level of anxiety.

\section{Clinical Significance}

In this global pandemic process, it is known that all dental healthcare providers' problems and needs are common, and the effects of the disease on the dental profession can be globalized. The current study provides preliminary data about the impact of COVID-19 on mental health for Turkish dentists. Findings can help to quantify support needs. In the face of the anxiety and stress displayed by dentists during COVID-19, mental coping mechanisms to stay calm and work efficiently are crucial.

\section{ACKNOWLedgments}

The authors deny any conflict of interests related to this study and would like to thank the voluntary, anonymous dentists who participated in the study and our colleagues who helped in the delivery of the survey.

\section{References}

1. Lu H, Stratton CW, Tang YW. Outbreak of pneumonia of unknown etiology in Wuhan, China: the mystery and the miracle. J Med Virol 2020;92(4):401-402. DOI: 10.1002/jmv.25678.

2. Huang C, Wang Y, Li X, et al. Clinical features of patients infected with 2019 novel coronavirus in Wuhan, China. Lancet 2020;395(10223):497506. DOI: 10.1016/S0140-6736(20)30183-5.

3. Sohrabi C, Alsafi Z, O'Neill N, et al. World Health Organization declares global emergency: a review of the 2019 novel coronavirus (COVID-19). Int J Surg 2020;76:71-76. DOI: 10.1016/j.jiju.2020.02.034.

4. Lu R, Zhao X, Li J, et al. Genomic characterisation and epidemiology of 2019 novel coronavirus: implications for virus origins and receptor binding. Lancet 2020;395(10224):565-574. DOI: 10.1016/S01406736(20)30251-8.

5. Peng X, Xu X, Li Y, et al. Transmission routes of 2019-nCoV and controls in dental practice. Int J Oral Sci 2020;12(1):9. DOI: 10.1038/s41368-0200075-9.

6. Fehr AR, Perlman S. Coronaviruses: an overview of their replication and pathogenesis. Methods Mol Biol 2015;1282:1-23. DOI: 10.1007/978-1-4939-2438-7_1.

7. Zhou $P$, Yang $X L$, Wang $X G$, et al. A pneumonia outbreak associated with a new coronavirus of probable bat origin. Nature 2020;579(7798):270-273. DOI: 10.1038/s41586-020-2012-7.

8. Liu P, Chen W, Chen JP. Viral Metagenomics revealed Sendai virus and coronavirus infection of Malayan pangolins (Manis javanica). Viruses 2019;11(11):979. DOI: 10.3390/v11110979.

9. WHO Situation Report - 162/30 July 2020 (https://www.who.int/ emergencies/diseases/novel-coronavirus-2019/situation-reports).

10. Lu CW, Liu XF, Jia ZF. 2019-nCoV transmission through the ocular surface must not be ignored. Lancet 2020;395(10224):e39. DOI: 10.1016/S0140-6736(20)30313-5.

11. Wang D, Hu B, Hu C, et al. Clinical characteristics of 138 hospitalized patients with 2019 novel coronavirus-infected pneumonia in Wuhan, China. JAMA 2020;323(11):1061-1069. DOI: 10.1001/ jama.2020.1585.

12. Chang D, Lin M, Wei L, et al. Epidemiologic and Clinical Characteristics of Novel Coronavirus Infections Involving 13 Patients Outside Wuhan, China [published online ahead of print, 2020 Feb 7]. JAMA 2020;323(11):1092-1093. DOI: 10.1001/jama.2020.1623.

13. Carlos WG, Dela Cruz CS, Cao B, et al. Novel Wuhan (2019-nCoV) Coronavirus. Am J Respir Crit Care Med 2020;201(4):7-8. DOI: 10.1164/ rccm.2014P7.

14. Wax RS, Christian MD. Practical recommendations for critical care and anesthesiology teams caring for novel coronavirus (2019-nCoV) patients. Directives concrètes à l'intention des équipes de soins intensifs et d'anesthésiologie prenant soin de patients atteints du coronavirus 2019-nCoV. Can J Anaesth 2020;67(5):568-576. DOI: 10.1007/s12630-020-01591-x.

15. Dutil S, Meriaux A, de Latremoille MC, et al. Measurement of airborne bacteria and endotoxin generated during dental cleaning. J Occup Environ Hyg 2009;6(2):121-130. DOI: 10.1080/15459620802633957.

16. Checchi L, Montevecchi M, Moreschi A, et al. Efficacy of three face masks in preventing inhalation of airborne contaminants in dental practice. J Am Dent Assoc 2005;136(7):877-882. DOI: 10.14219/jada. archive.2005.0288.

17. Information for Healthcare Professionals about Coronavirus Disease 2019 (COVID-19). https://www.cdc.gov/coronavirus/2019-ncov/hcp/ index.html.

18. He F, Deng Y, Li W. Coronavirus disease 2019: what we know? J Med Virol 2020;92(7):719-725. DOI: 10.1002/jmv.25766.

19. Althomairy SA, Baseer MA, Assery M, et al. Knowledge and attitude of dental health professionals about Middle East Respiratory Syndrome in Saudi Arabia. J Int Soc Prev Community Dent 2018;8(2):137-144. DOI: 10.4103/jispcd.JISPCD_9_18. 
20. Kharma MY, Alalwani MS, Amer MF, et al. Assessment of the awareness level of dental students toward Middle East Respiratory Syndromecoronavirus. J Int Soc Prev Community Dent 2015;5(3):163-169. DOI: 10.4103/2231-0762.159951.

21. Dugas MJ, Francis K. Review of the worry and anxiety questionnaire. Maltby J, Lewis, CA, Hill AP, editors. Commissioned reviews on 250 Psychological Tests. Lampeter, Wales: Edwin Mellen Press; 2000.

22. Ahmed MA, Jouhar R, Ahmed N, et al. Fear and practice modifications among dentists to combat novel coronavirus disease (COVID-19) outbreak. Int J Environ Res Public Health 2020;17(8):2821. DOI: 10.3390/ijerph17082821.

23. Pappa S, Ntella V, Giannakas T, et al. Prevalence of depression, anxiety, and insomnia among healthcare workers during the COVID19 pandemic: a systematic review and meta-analysis. Brain Behav Immun 2020;88:901-907. DOI: 10.1016/j.bbi.2020.05.026.

24. Consolo U, Bellini P, Bencivenni D, et al. Epidemiological aspects and psychological reactions to COVID-19 of dental practitioners in the Northern Italy districts of Modena and Reggio Emilia.
Int J Environ Res Public Health 2020;17(10):3459. DOI: 10.3390/ ijerph17103459.

25. Ge ZY, Yang LM, Xia JJ, et al. Possible aerosol transmission of COVID-19 and special precautions in dentistry. J Zhejiang Univ Sci B 2020;21(5):361-368. DOI: 10.1631/jzus.B2010010.

26. Shacham M, Hamama-Raz Y, Kolerman R, et al. COVID-19 factors and psychological factors associated with elevated psychological distress among dentists and dental hygienists in Israel. Int J Environ Res Public Health 2020;17(8):2900. DOI: 10.3390/ijerph17082900.

27. Lydeard, S. The questionnaire as a research tool. Fam Pract 1991;8: 84-91. DOI: 10.1093/fampra/8.1.84.

28. Özdin S, Bayrak Özdin S. Levels and predictors of anxiety, depression and health anxiety during COVID-19 pandemic in Turkish society: the importance of gender. Int J Soc Psychiatry 2020;66(5):504-511. DOI: 10.1177/0020764020927051.

29. Dong Y, Mo X, Hu Y, et al. Epidemiology of COVID-19 among children in China. Pediatrics 2020;145(6):e20200702. DOI: 10.1542/peds.2020-0702.

30. Republic of Turkey Ministry of Health; 2020. https://covid19.saglik. gov.tr/. 